\title{
Serum Triglyceride Lipase Concentrations are Independent Risk Factors for Coronary Artery Disease and In-Stent Restenosis
}

\author{
Xiaolan $\mathrm{Yu}^{1}$, Jianping $\mathrm{Lu}^{2}$, Jingjing $\mathrm{Li}^{3}$, Wen Guan ${ }^{4}$, Shaorong Deng ${ }^{3}$, Qing Deng ${ }^{1}, \mathrm{Hao} \mathrm{Ye}^{3}$, Wei $\mathrm{Han}^{3}$, \\ Yan $\mathrm{Yu}^{1}$ and Ruiyan Zhang ${ }^{5}$
}

Yan Yu and Ruiyan Zhang are joint senior authors.

${ }^{1}$ Shanghai Municipality Key Laboratory of Veterinary Biotechnology, School of Agriculture and Biology, Shanghai Jiao Tong University, Shanghai, China

${ }^{2}$ Department of Physical examinations, The Sixth People's Hospital, School of Medicine, Shanghai Jiao Tong University, Shanghai, China

${ }^{3}$ Laboratory of Regeneromics, School of Pharmacy, Shanghai Jiao Tong University, Shanghai, China

${ }^{4}$ Department of Biochemistry, Zhongshan School of Medicine, Sun Yat-sen University, Guangzhou, China

${ }^{5}$ Department of Cardiology, Ruijin Hospital, School of Medicine, Shanghai Jiao Tong University, Shanghai, China

Aim: Endothelial lipase (EL), hepatic lipase (HL), and lipoprotein lipase (LPL) are all triglyceride lipases and are associated with coronary artery disease (CAD). However, whether they can be simultaneous independent risk factors for CAD is unknown. In the present study, we investigated whether the three lipases can be independent risk factors simultaneously for $\mathrm{CAD}$ and whether combining these lipases could provide greater predictive power than high-density lipoprotein cholesterol (HDL-c) for the development of CAD.

Methods: Eighty-six patients with CAD and 65 healthy controls were enrolled in the study. Additionally, 38 patients who underwent one-year follow-up angiography after percutaneous coronary intervention with stent implantation were collected to investigate in-stent restenosis. Serum EL, HL, and LPL concentrations were measured and compared with other coronary risk factors.

Results: Serum EL and HL concentrations were both significantly increased in patients with CAD or in-stent restenosis, whereas serum LPL concentration was reduced significantly in patients with CAD. Multivariate logistic regression analysis indicated that the three lipases were simultaneous independent risk factors for CAD. However, only serum EL concentration was considered an independent risk factor for in-stent restenosis. Importantly, the receiver operating characteristic curve showed that the combined measurement of the three lipases displayed better predictive power than HDL-c or any one of the three lipases for CAD.

Conclusions: Serum EL concentration was an independent risk factor for both CAD and in-stent restenosis. Moreover, the combined assessment of serum EL, HL, and LPL concentrations as multiple risk factors provided potent predictive power for CAD.

\section{See editorial vol. 26: 758-759}

Key words: Coronary artery disease, Endothelial lipase, Hepatic lipase, Lipoprotein lipase, In-stent restenosis, Risk factor

\section{Introduction}

Coronary artery disease (CAD) has become one of the major diseases that threaten human health and longevity. Therefore, early detection of those at high risk of CAD is critical and will enable the administration of interventional approaches such as dietary and lifestyle modifications, pharmacological therapies, and

Address for correspondence: Ruiyan Zhang, Department of Cardiology, No.197, Rui Jin Er Road, Shanghai, 200025, China

E-mail address: zhangruiyan@263.net

Received: September 14, 2018 Accepted for publication: December 4, 2018

Copyright@2019 Japan Atherosclerosis Society

This article is distributed under the terms of the latest version of CC BY-NC-SA defined by the Creative Commons Attribution License. 
other preventative means.

Lipid metabolism plays an important role in atherosclerosis and is involved in CAD. High-density lipoprotein cholesterol (HDL-c) and low-density lipoprotein cholesterol (LDL-c) are crucial lipoproteins involved in lipid metabolism and are well-known risk factors for CAD. However, a large proportion of patients with myocardial infarction have normal concentrations of HDL-c, and pharmacological interventions demonstrate that HDL-c increases are not consistently associated with a reduction of the CAD risk ${ }^{1)}$. Moreover, the overlap of blood LDL-c distributions among patients with and without CAD result in falsepositive and false-negative detection rates ${ }^{2)}$. Therefore, it is of great clinical significance to identify the novel risk factors with lipid metabolism or CAD.

Endothelial lipase (EL), hepatic lipase (HL), and lipoprotein lipase (LPL) are members of the triglyceride lipase gene subfamily and play crucial roles in plasma lipoprotein metabolism ${ }^{3-5}$. EL is unique in its expression by endothelial cells ${ }^{6}$, and is a regulator of plasma HDL-c levels ${ }^{3}$. In addition, plasma EL concentration is increased in patients with metabolic syndrome and associated with coronary atherosclerosis ${ }^{7)}$, and plasma EL activity is associated with the risks for $\mathrm{CAD}^{8)}$. HL is primarily secreted by hepatocytes and to a lesser extent by the macrophage ${ }^{4)}$, and is mainly involved in the metabolism of LDL and $\mathrm{HDL}^{9)}$. It has been reported that low plasma HL activity is associated with hypertriglyceridemia and $\mathrm{CAD}^{10,11)}$. However, high serum HL concentration is associated with increased CAD risk ${ }^{12)}$. LPL is mainly expressed in adipose tissue, skeletal, and cardiac muscle, and catalyzes the hydrolysis of triglycerides in circulating lipoproteins ${ }^{5)}$. Lower LPL concentration and activity are observed in patients with metabolic syndrome or hypertriglyceridemia or $\mathrm{CAD}^{11,13-16)}$.

These findings indicate that EL, HL, and LPL are all associated with CAD. However, whether they can all be independent risk factors simultaneously for CAD is unknown. In addition, it is suggested that combining multiple risk factors can be more accurately and efficiently quantified to identify patients at risk for $\mathrm{CAD}^{17)}$. Considering the fact that heparin injection is not quite standardized and accepted by patients and may also affect lipoprotein metabolism ${ }^{12,18)}$, in our study, we chose to detect the serum concentrations of lipases without heparin administration. We tested the hypothesis that serum EL, HL, and LPL concentrations would all be simultaneous independent risk factors for CAD and when combined the three lipases would provide the higher predictive power than HDL-c or LDL-c for CAD. We also studied a small subset of patients who underwent one-year follow-up angiography after percutaneous coronary intervention (PCI) with stent implantation to investigate the relationship between the three lipases and in-stent restenosis.

\section{Methods}

Subjects

In this study, we enrolled the patients who underwent coronary angiography (CAG) for the first time at the Shanghai JiaoTong University of Medicine, Ruijin Hospital, due to chest pain, or abnormal electrocardiogram between January 1, 2013, and December 31,2015 . The group included 86 subjects who had more than one of main coronary artery with $>$ $50 \%$ luminal diameter stenoses found on CAG and were diagnosed with CAD.

We also enrolled another 38 patients who underwent a one-year routine follow-up angiography after PCI with drug-eluting stent implantation at the Ruijin Hospital, between January 1, 2013, and December 31, 2015.

Healthy controls included 65 persons who had a normal electrocardiogram without abnormal findings, such as diabetes mellitus, hypertension, liver disease, or hyperlipidemias at the Shanghai JiaoTong University of Medicine, the Sixth People's Hospital, between January 1, 2015, and December 31, 2015.

All subjects provided written informed consent, and the study protocol was approved by the Ethics Committee of Shanghai JiaoTong University.

\section{CAG Study}

CAG was performed using transfemoral or transbrachial approaches via a standard technique according to the Judkins method ${ }^{19)}$. To evaluate the degree of vascular stenosis, two experienced cardiologists conducted diagnoses in parallel. Narrowing of $\geq 50 \%$ in more than one of the main coronary arteries was judged as CAD.

To identify whether patients have in-stent restenosis, angiograms obtained before, and one year after PCI were reviewed and analyzed by two experienced cardiologists. Restenosis was defined as the recurrence of luminal diameter stenosis of $>50 \%$ within the stent or in the $5-\mathrm{mm}$ proximal or distal segments adjacent to the stent.

\section{Evaluation of Risk Factors}

Age, gender, body mass index (BMI), hypertension, diabetes mellitus, fasting blood glucose, total cholesterol, total triglyceride, LDL-c, HDL-c, serum EL concentration, serum HL concentration, and serum LPL concentration were investigated as risk fac- 
Table 1. Baseline clinical characteristics for CAD

\begin{tabular}{lccr}
\hline & Controls $(n=65)$ & CAD $(n=86)$ & $P$ value \\
\hline Male/Female & $44 / 21$ & $67 / 19$ & 0.111 \\
Age $(\mathrm{y})$ & $54.06 \pm 11.48$ & $60.44 \pm 9.58$ & $<0.001$ \\
Hypertension, $n(\%)$ & $/$ & $57(66.28 \%)$ & $/$ \\
Diabetes mellitus, $n(\%)$ & $/$ & $16(18.60 \%)$ & $<0.001$ \\
BMI $\left(\mathrm{kg} / \mathrm{m}^{2}\right)$ & $23.01 \pm 2.66$ & $25.35 \pm 2.81$ & $<0.001$ \\
SBP $(\mathrm{mmHg})$ & $122.17 \pm 16.48$ & $138.64 \pm 21.65$ & 0.033 \\
DBP $(\mathrm{mmHg})$ & $75.31 \pm 10.90$ & $79.00 \pm 9.80$ & 0.002 \\
FBG $(\mathrm{mmol} / \mathrm{L})$ & $5.11 \pm 0.81$ & $5.72 \pm 1.47$ & 0.345 \\
TG $(\mathrm{mmol} / \mathrm{L})$ & $1.43 \pm 0.81$ & $1.55 \pm 0.74$ & 0.883 \\
TCH $(\mathrm{mmol} / \mathrm{L})$ & $4.47 \pm 0.64$ & $4.49 \pm 0.94$ & 0.398 \\
LDL-c $(\mathrm{mmol} / \mathrm{L})$ & $2.58 \pm 0.58$ & $2.48 \pm 0.89$ & $<0.001$ \\
HDL-c $(\mathrm{mmol} / \mathrm{L})$ & $1.39 \pm 0.30$ & $1.05 \pm 0.32$ & $/$ \\
Statins $(\%)$ & $/$ & $62(72.09 \%)$ & $/$ \\
Atorvastatin & $/$ & $31(36.05 \%)$ & $/$ \\
Pravastatin & $/$ & $24(27.91 \%)$ & $/$ \\
Rosuvastatin & $/$ & $5(5.81 \%)$ & $2(2.32 \%)$ \\
Simvastatin & $/$ & 2.8 & $/$ \\
\hline
\end{tabular}

Statistical comparisons between the two groups were performed using Student's $t$-test and chi-squared test for gender. Values are means \pm standard deviation (SD) or proportions (\%). CAD, coronary artery disease; BMI, body mass index; SBP, systolic blood pressure; DBP, diastolic blood pressure; FBG, fast blood glucose; TCH, total cholesterol; TG, total triglyceride; LDL-c, low-density lipoprotein cholesterol; HDL-c, high-density lipoprotein cholesterol.

tors for CAD or in-stent restenosis. Hypertension was defined as systolic blood pressure $\geq 140 \mathrm{mmHg}$ and diastolic blood pressure $\geq 90 \mathrm{mmHg}$ or the presence of prescribed antihypertensive treatment. Diabetes mellitus was defined as fasting blood glucose levels of $\geq 6.1 \mathrm{mmol} / \mathrm{L}$ and/or a history of diabetes mellitus. BMI was calculated as the body weight $(\mathrm{kg})$ divided by the square of height $\left(\mathrm{m}^{2}\right)$.

\section{Blood Sampling and Measurement of Lipids}

Blood samples were taken in the morning after $12 \mathrm{~h}$ of fasting. Serum was separated within $1 \mathrm{~h}$, and the samples used for EL, LPL, and HL concentration measurements were frozen at $-80^{\circ} \mathrm{C}$ until analysis. Total cholesterol, total triglyceride, LDL-c, and HDL-c were measured enzymatically on a Hitachi 912 analyzer (Roche Diagnostics, Nghiem, Germany). Plasma glucose concentration was measured by the glucose oxidase method.

The serum EL concentration was measured using the EL-ELISA (enzyme linked immunosorbent assay) developed by Ishida et al. ${ }^{20)}$. Serum HL concentration was determined by HL-ELISA developed by Miyashita $e t$ al. ${ }^{12)}$. Serum LPL concentration was measured by LPL-ELISA described by Shirakawa et al. ${ }^{21)}$. All techniques used a monoclonal antibody-based sandwich ELISA from IBL (EL, NO.27182; HL, NO.27180; LPL, NO.27184). Each intra-assay and inter-assay CVs (coefficients of variability) were less than $5 \%$, and specificity was $100 \%$. Cross-reactivity with the other two lipases was less than $0.1 \%$.

\section{Statistical Analysis}

All statistical analysis was performed using SPSS18.0 or Medcalc statistical software. Data are reported as median \pm interquartile (IQR) or mean \pm standard deviation (SD) or proportions (\%). Betweengroup comparisons were performed using Student's $t$-test or chi-squared test where appropriate. Multivariate logistic regression analysis was used to determine the independent risk factors for CAD or in-stent restenosis with odds ratios (OR) and 95\% confidence intervals $(\mathrm{CI})$. The receiver operating characteristic (ROC) curve analysis with area under the curve (AUC) was used to assess the predictive power of risk factors for CAD or in-stent restenosis ${ }^{22)}$. Combined AUC was based on the predicted probabilities using the multivariable model from the logistic regression analysis of the three lipases ${ }^{23)}$. A $P$ value of less than 0.05 was considered significant.

\section{Results}

\section{Subject Characteristics of CAD}

Baseline clinical characteristics for controls and CAD are shown in Table 1. Age, BMI, systolic blood 


\section{A}
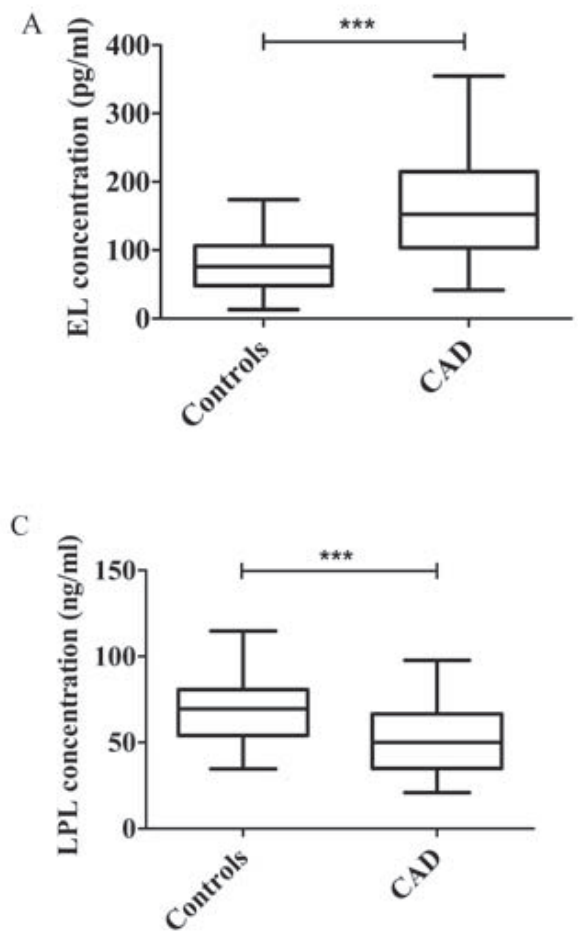

B

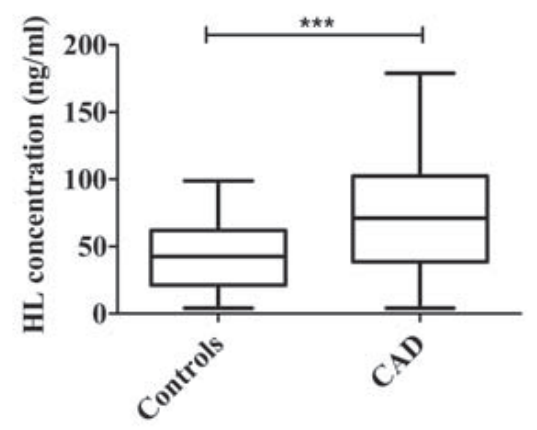

Fig. 1. Serum EL and HL concentrations were significantly increased in patients with CAD $\mathrm{A}, \mathrm{B}$, and $\mathrm{C}$ present the comparison of serum EL, HL, and LPL concentrations between controls and patients with CAD, respectively. Controls $(n=65)$ and CAD $(n=86)$. Data were median \pm interquartile (IQR), Between-group comparisons were performed by Student's $t$-test; ${ }^{*} P<0.05$, ${ }^{* *} P<0.01,{ }^{* * *} P<0.001$.

pressure, diastolic blood pressure, and fasting blood glucose were significantly higher in patients with CAD than healthy controls. Considering the serum lipid concentrations, the total triglyceride, total cholesterol, and LDL-c concentrations were not significantly different between the two groups because of statin therapy. However, serum HDL-c concentration was significantly reduced in patients with CAD.

\section{Serum EL and HL Concentrations were Significantly Increased in Patients with CAD}

Comparison of the three lipases between patients with CAD and controls is shown in Fig. 1. Both serum EL and HL concentrations were significantly higher in patients with CAD than controls (EL, $165.49 \pm 74.35 \mathrm{pg} / \mathrm{mL}$ vs. $83.21 \pm 42.55 \mathrm{pg} / \mathrm{mL}, P<$ $0.001 ; \mathrm{HL}, 75.31 \pm 42.87 \mathrm{ng} / \mathrm{mL}$ vs. $42.87 \pm 24.98$ $\mathrm{ng} / \mathrm{mL}, P<0.001$, Fig. $1 \mathrm{~A}$ and $1 \mathrm{~B})$. However, serum LPL concentration was reduced significantly in patients with CAD $(52.58 \pm 19.44 \mathrm{ng} / \mathrm{mL}$ vs. $71.76 \pm$ $22.90 \mathrm{ng} / \mathrm{mL}, P<0.001$, Fig. 1C). This suggests that serum EL and HL concentrations were both significantly increased, while serum LPL concentration was significantly decreased in the patients with CAD.
The Three Lipases were Simultaneous Independent Risk Factors for CAD

To further study the relationship between the three lipases and CAD, we performed univariate and multivariate logistic regression analysis (Table 2). After adjusting for all other possible risk factors, serum EL, HL, and LPL concentrations were all independent risk factors simultaneously for $\mathrm{CAD}$ with an adjusted OR of 1.040 (95\% CI: 1.017-1.063, $P<0.05$ ), 1.032 (95\% CI: $1.007-1.058 ; P<0.05)$ and $0.936(95 \%$ CI, 0.890-0.986; $P<0.05)$, respectively. Therefore, the results of regression analysis indicated that the three lipases all played independent roles in CAD.

Combination of the Three Lipases Provided the Higher Predictive Power than HDL-c for CAD

We performed the ROC analysis to compare the predictive power of the three lipases and HDL-c for CAD. As shown in Fig. 2, serum EL concentration showed the greater predictive power for CAD when compared with HDL-c, serum HL, or LPL concentrations (EL, AUC: $0.837,95 \% \mathrm{CI}: 0.763-0.896, P<$ 0.001; HDL-c, AUC: 0.783, 95\% CI: 0.702-0.851, $P<0.001$; HL, AUC: $0.720,95 \%$ CI: 0.635-0.795, 
Table 2. Univariate and Multivariate logistic regression analysis for CAD

\begin{tabular}{|c|c|c|c|c|c|c|}
\hline \multirow[t]{2}{*}{ Risk factors } & \multicolumn{3}{|c|}{ Univariate analysis } & \multicolumn{3}{|c|}{ Multivariate analysis } \\
\hline & OR & $95 \% \mathrm{CI}$ & $P$ & OR & $95 \% \mathrm{CI}$ & $P$ \\
\hline Gender & 1.683 & $0.813-3.485$ & 0.161 & & & \\
\hline Age (y) & 1.059 & $1.025-1.094$ & $<0.001$ & 1.017 & $0.936-1.104$ & 0.691 \\
\hline BMI $\left(\mathrm{kg} / \mathrm{m}^{2}\right)$ & 1.382 & $1.199-1.593$ & $<0.001$ & 1.204 & $0.901-1.607$ & 0.209 \\
\hline $\mathrm{SBP}(\mathrm{mmHg})$ & 1.049 & $1.027-1.072$ & $<0.001$ & 1.180 & $1.062-1.312$ & 0.002 \\
\hline DBP (mmHg) & 1.036 & $1.003-1.070$ & 0.033 & 0.871 & $0.769-0.987$ & 0.030 \\
\hline $\mathrm{FBG}(\mathrm{mmoL} / \mathrm{L})$ & 1.587 & $1.143-2.203$ & 0.006 & 1.130 & $0.530-2.409$ & 0.753 \\
\hline TG (mmoL/L) & 1.234 & $0.798-1.906$ & 0.344 & & & \\
\hline $\mathrm{TCH}(\mathrm{mmoL} / \mathrm{L})$ & 1.029 & $0.693-1.528$ & 0.888 & & & \\
\hline LDL-c (mmoL/L) & 0.84 & $0.550-1.284$ & 0.84 & & & \\
\hline HDL-c (mmoL/L) & 0.039 & $0.011-0.133$ & $<0.001$ & 0.053 & $0.003-1.037$ & 0.053 \\
\hline $\mathrm{EL}(\mathrm{pg} / \mathrm{mL})$ & 1.026 & $1.017-1.036$ & $<0.001$ & 1.040 & $1.017-1.063$ & 0.011 \\
\hline $\mathrm{HL}(\mathrm{ng} / \mathrm{mL})$ & 1.028 & $1.015-1.041$ & $<0.001$ & 1.032 & $1.007-1.058$ & 0.012 \\
\hline LPL (ng/mL) & 0.956 & $0.938-0.974$ & $<0.001$ & 0.936 & $0.890-0.986$ & 0.014 \\
\hline
\end{tabular}

OR: odds ratio, CI: confidence interval; $(n=151)$.

The multiple logistic regression model used in the analysis for the three lipases was adjusted for the following covariates: age, BMI, SBP, DBP, FBG and HDL-c. BMI, body mass index; SBP, systolic blood pressure; DBP, diastolic blood pressure; FBG, fast blood glucose; TCH, total cholesterol; TG, total triglyceride; LDL-c, low-density lipoprotein cholesterol; HDL-c, high-density lipoprotein cholesterol.

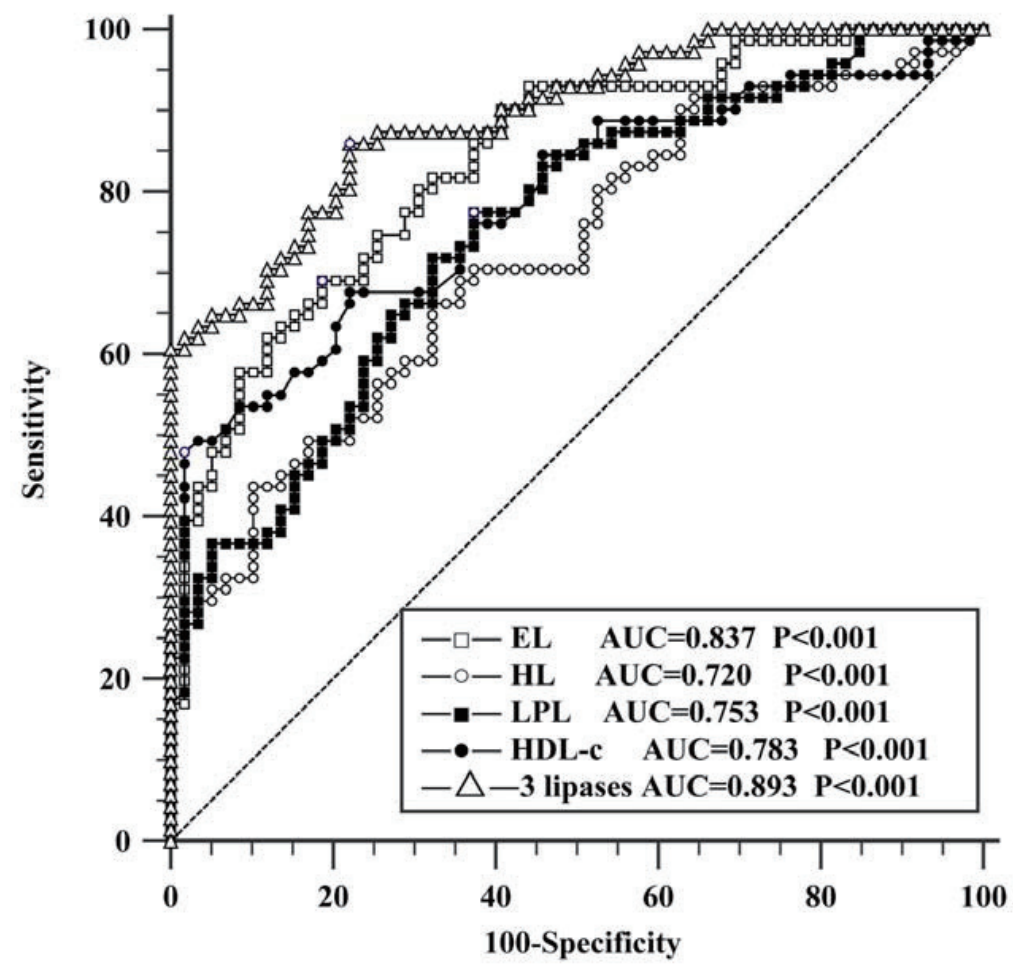

Fig. 2. Combination of the three lipases provided the higher predictive power than HDL-c for CAD

Receiver operating characteristic (ROC) curve was utilized to evaluate the predictive power of the three lipases and HDL-c for CAD. Empty triangles pertain to the combined three lipases together, which had the best predictive power (area under the curve $($ AUC $)=0.893, P<0.001)$. The dashed 45-degree line is the line of nondiscrimination. 
Table 3. Baseline clinical characteristics for in-stent restenosis

\begin{tabular}{|c|c|c|c|c|}
\hline & All subjects $(n=38)$ & NO ISR $(n=28)$ & $\operatorname{ISR}(n=10)$ & $P$ value \\
\hline Male/Female & $28 / 10$ & $20 / 8$ & $8 / 2$ & 0.470 \\
\hline Age (y) & $64.16 \pm 8.64$ & $63.68 \pm 8.99$ & $65.50 \pm 7.86$ & 0.574 \\
\hline Hypertension, $n(\%)$ & $31(81.58 \%)$ & $22(78.57 \%)$ & $9(90 \%)$ & 0.650 \\
\hline Diabetes mellitus, $n(\%)$ & $15(39.47 \%)$ & $10(35.71 \%)$ & $5(50 \%)$ & 0.473 \\
\hline BMI $\left(\mathrm{kg} / \mathrm{m}^{2}\right)$ & $25.01 \pm 2.88$ & $24.88 \pm 2.55$ & $25.37 \pm 3.79$ & 0.651 \\
\hline $\mathrm{TG}(\mathrm{mmol} / \mathrm{L})$ & $1.41 \pm 0.63$ & $1.36 \pm 0.57$ & $1.56 \pm 0.79$ & 0.393 \\
\hline $\mathrm{TCH}(\mathrm{mmol} / \mathrm{L})$ & $3.82 \pm 1.08$ & $3.70 \pm 0.91$ & $4.15 \pm 1.48$ & 0.268 \\
\hline LDL-c (mmol/L) & $2.16 \pm 0.90$ & $2.05 \pm 0.77$ & $2.46 \pm 1.18$ & 0.218 \\
\hline HDL-c (mmol/L) & $1.16 \pm 0.25$ & $1.17 \pm 0.22$ & $1.15 \pm 0.34$ & 0.862 \\
\hline Statins (\%) & $38(100 \%)$ & $28(100 \%)$ & $10(100 \%)$ & 1 \\
\hline Atorvastatin & $26(68.42 \%)$ & $20(71.43 \%)$ & $6(60 \%)$ & 0.694 \\
\hline Pravastatin & $2(5.26 \%)$ & $2(7.14 \%)$ & I & I \\
\hline Rosuvastatin & $9(23.68 \%)$ & $5(17.86 \%)$ & $4(40 \%)$ & 0.205 \\
\hline Simvastatin & $1(2.63 \%)$ & $1(3.57 \%)$ & l & l \\
\hline
\end{tabular}

Statistical comparisons between NO ISR (without in-stent restenosis) and ISR (with in-stent restenosis) were performed using Student's $t$-test and chi-squared test for categorical variables. Values are means \pm standard deviation (SD) or proportions (\%). BMI, body mass index; SBP, systolic blood pressure; DBP, diastolic blood pressure; FBG, fast blood glucose; TCH, total cholesterol; TG, total triglyceride; LDL-c, low-density lipoprotein cholesterol; HDL-c, high-density lipoprotein cholesterol.

$P<0.001$; LPL, AUC: 0.753, 95\% CI: 0.669-0.824, $P<0.001)$. Importantly, combining the three lipases provided the best predictive power for CAD (three lipases, AUC: $0.893,95 \%$ CI: $0.827-0.941, P<$ $0.001)$. Thus, these data suggest that among the three lipases, serum EL concentration alone would be a better indicator than HDL-c for CAD, and combined serum EL, HL, and LPL concentrations as multiple risk factors could be more accurate to identify patients at risk for $\mathrm{CAD}$.

\section{Subject Characteristics for In-Stent Restenosis}

Table 3 indicates the demographic data from the 38 patients who underwent a one-year routine followup angiography at the Ruijin Hospital after PCI with drug-eluting stent implantation. In this study, 31 patients had hypertension, 15 patients had diabetes mellitus, and all patients were on statin therapy. The 38 patients composed of 28 patients without in-stent restenosis and 10 patients with in-stent restenosis based on the analysis of the angiogram. Age, BMI, total triglyceride, total cholesterol, LDL-c, and HDL-c concentrations were not significantly different between the two groups.

\section{Serum EL and HL Concentrations were Significantly Increased in Patients with In-Stent Restenosis}

Both serum EL and HL concentrations were significantly increased in patients with in-stent restenosis compared to patients without in-stent restenosis (EL, $163.33 \pm 52.59 \mathrm{pg} / \mathrm{mL}$ vs. $111.42 \pm 60.52 \mathrm{pg} / \mathrm{mL}, P<$
0.05; HL, $87.21 \pm 46.63 \mathrm{ng} / \mathrm{mL}$ vs. $52.24 \pm 23.21 \mathrm{ng} /$ $\mathrm{mL}, P<0.05$, Fig. 3A and 3B). However, serum LPL concentration was not significantly different between the two groups $(69.82 \pm 22.62 \mathrm{ng} / \mathrm{mL}$ vs. $63.88 \pm$ $25.61 \mathrm{ng} / \mathrm{mL}, P=0.33$, Fig. $3 \mathrm{C}$ ). These results suggest that only the concentrations of EL and HL were significantly increased in patients with in-stent restenosis.

Serum EL Concentration was an Independent Risk Factor for In-Stent Restenosis

To further investigate the relationship between the three lipases and in-stent restenosis, we performed univariate and multivariate logistic regression (Table 4). The result showed that only serum EL concentration remained as an independent risk factor for instent restenosis after adjusting for HDL-c, serum HL, and LPL concentrations, with an adjusted OR of 1.017 (95\% CI: 1.000-1.034; $P<0.05$ ). Thus, the analysis indicated that among the three lipases, only serum EL concentration had an independent role in in-stent restenosis.

Serum EL and HL Concentrations Displayed the Higher Predictive Power than HDL-c for In-Stent Restenosis

Considering serum HL and LPL concentration were not independent risk factors for in-stent restenosis, we evaluated the predictive power of serum EL, $\mathrm{HL}$, and LPL concentrations alone for in-stent restenosis by ROC analysis. The ROC analysis suggested 
A

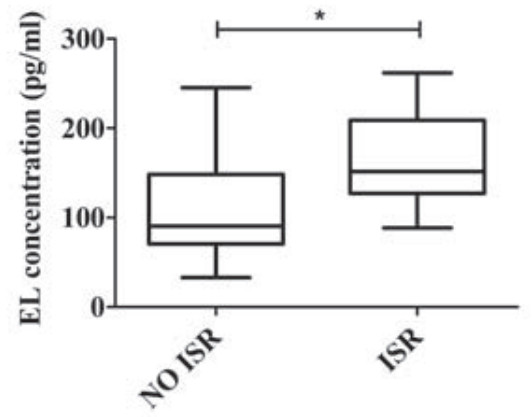

C

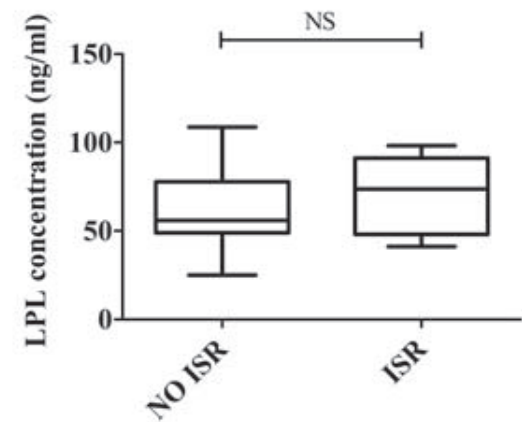

B

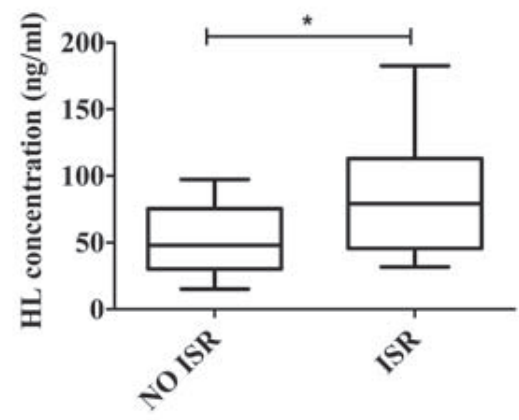

Fig. 3. Serum EL and HL concentrations were significantly increased in patients with instent restenosis

$\mathrm{A}, \mathrm{B}$, and C present the comparison of serum EL, HL, and LPL concentrations between without and with in-stent restenosis, respectively. NO ISR (without in-stent restenosis, $n=28$ ), ISR (with in-stent restenosis, $n=10$ ). Data were median \pm interquartile (IQR), Between-group comparisons were performed by Student's $t$-test; ${ }^{*} P<0.05$; NS, not significant.

Table 4. Univariate and Multivariate logistic regression analysis for in-stent restenosis

\begin{tabular}{|c|c|c|c|c|c|c|}
\hline \multirow[t]{2}{*}{ Risk factors } & \multicolumn{3}{|c|}{ Univariate analysis } & \multicolumn{3}{|c|}{ Multivariate analysis } \\
\hline & OR & $95 \% \mathrm{CI}$ & $P$ value & OR & $95 \% \mathrm{CI}$ & $P$ value \\
\hline Gender & 1.600 & $0.277-9.235$ & 0.599 & & & \\
\hline Age (y) & 1.027 & $0.939-1.123$ & 0.564 & & & \\
\hline Hypertension & 2.455 & $0.258-23.395$ & 0.435 & & & \\
\hline Diabetes & 1.800 & $0.418-7.757$ & 0.430 & & & \\
\hline BMI $\left(\mathrm{kg} / \mathrm{m}^{2}\right)$ & 1.063 & $0.822-1.376$ & 0.641 & & & \\
\hline TG (mmoL/L) & 1.629 & $0.538-4.935$ & 0.388 & & & \\
\hline $\mathrm{TCH}(\mathrm{mmoL} / \mathrm{L})$ & 1.446 & $0.752-2.782$ & 0.269 & & & \\
\hline LDL-c (mmoL/L) & 1.622 & $0.745-3.533$ & 0.223 & & & \\
\hline HDL-c (mmoL/L) & 0.764 & $0.041-14.176$ & 0.857 & 0.250 & $0.006-9.626$ & 0.457 \\
\hline $\mathrm{EL}(\mathrm{pg} / \mathrm{mL})$ & 1.014 & $1.001-1.027$ & 0.035 & 1.017 & $1.000-1.034$ & 0.049 \\
\hline $\mathrm{HL}(\mathrm{ng} / \mathrm{mL})$ & 1.033 & $1.002-1.065$ & 0.036 & 1.040 & $0.994-1.089$ & 0.089 \\
\hline LPL (ng/mL) & 1.010 & $0.980-1.040$ & 0.528 & 1.049 & $0.995-1.106$ & 0.076 \\
\hline
\end{tabular}

OR: odds ratio, CI: confidence interval; $(n=38)$.

The multiple logistic regression model used in the analysis for serum EL concentration was adjusted for HDL-c, serum HL and LPL concentrations. BMI, body mass index; SBP, systolic blood pressure; DBP, diastolic blood pressure; FBG, fast blood glucose; TCH, total cholesterol; TG, total triglyceride; LDL-c, low-density lipoprotein cholesterol; HDL-c, high-density lipoprotein cholesterol. 


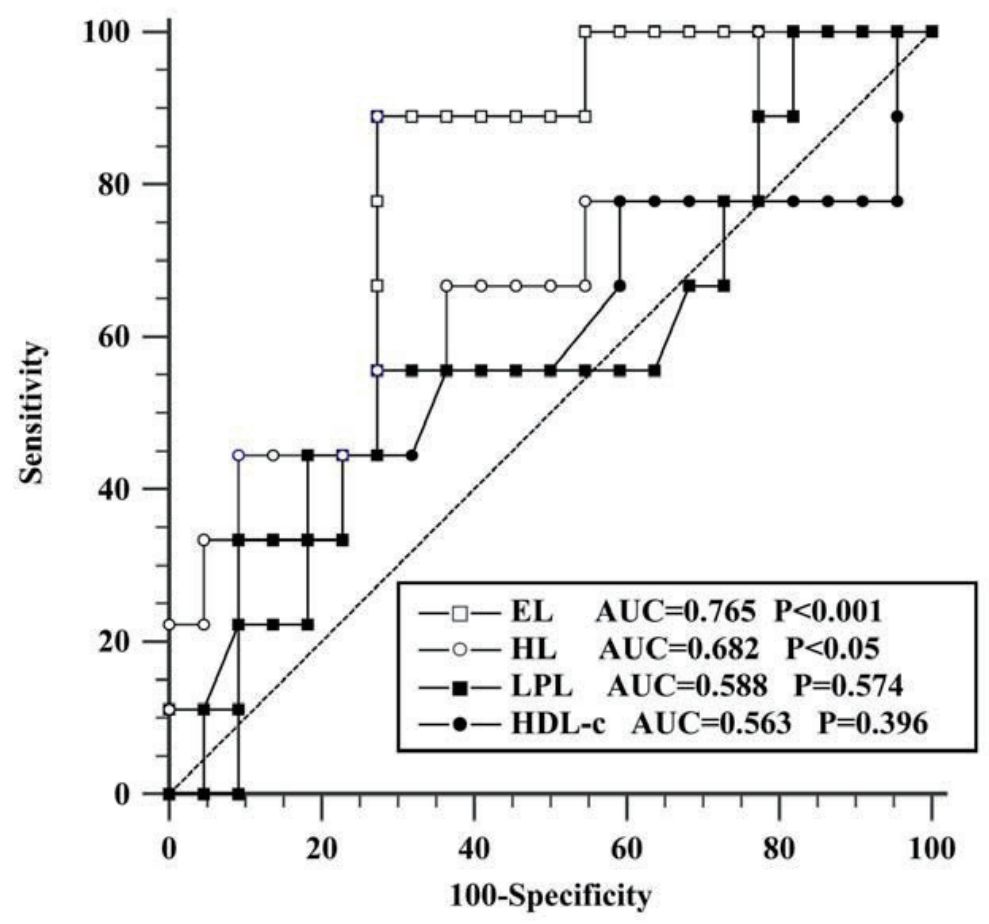

Fig.4. Serum EL concentration displayed the higher predictive power than HDL-c for in-stent restenosis

Receiver operating characteristic (ROC) curve was utilized to evaluate the predictive power of the three lipases and HDL-c for in-stent restenosis. Empty squares present the EL alone, which had the best discrimination ability (area under curve (AUC) $=0.765, P$ $<0.001)$. The dashed 45-degree line is the line of nondiscrimination.

that the predictive power of EL (AUC: $0.765,95 \%$ CI: $0.579-0.898, P<0.001$ ) and HL (AUC: 0.682, 95\% CI: $0.491-0.837, P<0.05)$ were better than that of HDL-c (AUC: 0.563 , 95\% CI: 0.374-0.740, $P=$ 0.40 , Fig. 4) for in-stent restenosis. It suggested that serum EL and HL concentrations would be strong indicators for in-stent restenosis even when patients had normal HDL-c levels after the PCI.

\section{Discussion}

Consistent with our original hypothesis, serum EL, HL, and LPL concentrations were simultaneous independent risk factors for $\mathrm{CAD}$, and the combination of the three lipases as multiple risk factors could provide improved predictive power relative to HDL-c for CAD. We also found serum EL concentration to be an independent risk factor for in-stent restenosis, and serum EL and HL concentrations displayed a better predictive power than HDL-c for in-stent restenosis.

In our study, we found serum EL and HL concentrations were significantly increased while serum LPL concentration was significantly reduced in the patients with CAD, which is consistent with previous studies ${ }^{12,14,20)}$. Although these lipases are all triglyceride lipases, they were simultaneous independent risk factors for CAD by the multivariate analysis, which suggested that the three lipases play independent roles in the development of CAD. Further, serum EL concentration was the strongest risk factor among the three lipases, and it alone displayed a higher predictive power than HDL-c for CAD. These results suggest that serum EL would be a better indicator than HDL-c for CAD. Importantly, combining the three lipases could raise the AUC to reach up to 0.893 and was significantly higher than that of HDL-c alone or three lipases alone, which supports that CAD is a progressive disorder and its risk is best determined using multiple risk factors ${ }^{17)}$.

Despite PCI being a well-established and useful technique for $\mathrm{CAD}$, various other factors reduce instent restenosis. Insulin resistance and inflammation are well-known major risk factors for restenosis ${ }^{24-26)}$. Considering that EL, HL, and LPL were associated with insulin resistance or inflammation ${ }^{27-31)}$, we investigated the relationship between the three lipases and restenosis. We found that only serum EL and HL con- 
centrations were significantly increased in patients with in-stent restenosis. In addition, serum EL and HL concentrations displayed higher predictive power than HDL-c for patients with in-stent restenosis and serum EL concentration was an independent risk factor for these patients. These results suggest that serum EL would be a strong indicator for in-stent restenosis even if other risk factors especially HDL-c were at normal levels among patients who had routine followup angiography after PCI. We speculate that ROC and multiple logistic regression analysis suggest that the abilities of serum EL concentration to predict instent restenosis might be associated with inflammation other than HDL-c. Unfortunately, in the present study, our basic clinical characteristics did not include inflammation markers. Thus, these markers should be measured in future investigations to provide improved biochemical measurements and clinical utility for the prediction of in-stent restenosis. Of note, however, serum LPL concentration was not an independent risk factor for in-stent restenosis, which is inconsistent with a previous report ${ }^{32)}$. This effect could be due to one or both of the following: 1) the study by Takashi evaluated the relationship between LPL and bare metal stent restenosis rather than the drug-eluting stent, as observed in our study. 2) Instead of setting a cutting value for LPL to determine the independent risk factor of restenosis as they did, we set LPL as a continuous variable.

In addition, we also found high serum HL and low serum LPL concentrations were significantly associated with the severity of lesions in our preliminary study (Supplementary Fig. 1). Furthermore, they were both independent determinants of coronary lesions with high $t$-values after adjusting other risk factors by multivariate linear regression analysis (Supplementary Table 1). It suggests that serum LPL and HL concentrations might be used to effectively distinguish the severity of lesions in the future. Moreover, a previous report has shown that K-877 (pemafibrite), as a novel selective PPAR $\alpha$ modulator (SPPARM $\alpha$ ), substantially increases fasting LPL activity and attenuates hypertriglyceridemia. Combined with our report, these results suggest that patients with CAD may benefit from the novel drug ${ }^{33)}$.

Given that EL, HL, and LPL were all triglyceride lipases, we compared the correlations among the three lipases to one another (data not being shown). Because heparinization is not standardized and may affect lipoprotein metabolism ${ }^{12,18)}$. we chose to detect the concentrations of lipases in the serum. It has been reported that heparin administration is not always necessary for EL concentration ${ }^{20)}$. Recent studies have shown the importance of measuring LPL or HL con- centration in serum without heparin administration ${ }^{12,34)}$. We found serum EL concentration had a significant negative correlation with serum LPL concentration in patients with CAD or in-stent restenosis. However, the mechanism needs to be further elucidated in the future. In contrast, serum HL concentration was not correlated with serum EL or LPL concentrations. It was slightly different from the previous study in which they found a weak but significant, positive correlation between post-heparin plasma (PHP) EL and HL in obese men ${ }^{35)}$. This finding suggested that serum concentrations of EL and HL play different roles from those in plasma. On the other hand, it suggests that the clinical significance of these lipases in the serum is very critical because serum concentrations may reflect the physiological role in the whole body more precisely than their presence in PHP.

In our study, we also performed a correlation analysis of the three lipases and plasma lipoprotein levels. However, the results showed that there were no significant correlations in patients with CAD or restenosis. This lack of association in our study is likely due to the fact that statin therapy controls plasma lipoprotein levels in patients. It could also suggest there is another mechanism besides lipid metabolism for lipases to modulate atherosclerosis. Plasma EL concentration was shown to be associated with inflammation ${ }^{27,28)}$. Some studies showed that HL was associated with insulin resistance and inflammation ${ }^{29,36)}$, and LPL was significantly associated with insulin resistance, adiponectin, and inflammation ${ }^{30,37,38)}$. Therefore, in our study, we like to propose that triglyceride lipases affecting CAD or in-stent restenosis could work through other mechanisms such as inflammation. However, the precise mechanism needs further elucidation.

This investigation has some limitations. Most of our patients with CAD were on atorvastatin or rosuvastatin-therapy, and this could have influenced the results. In addition, we compared the parameters between CAD patients without statin therapy and the controls without statin therapy. The results still showed that serum HDL-c and LPL concentrations were significantly reduced, and serum EL and HL concentrations were significantly increased in CAD patients. However, the effect of these statins on the concentrations of these lipases in CAD patients cannot be neglected. Some reports indicated that these statins did not significantly affect the concentrations of these lipases ${ }^{39}$, 40), while other reports indicated that they impacted these lipases effectively in patients with hypercholesterolemia ${ }^{41-44)}$. It is also worth noting that our sample size is relatively small, especially for the sample of patients with in-stent restenosis. Finally, this 
investigation was retrospective, which limited our ability to infer a causal relationship between the three lipases and CAD. Despite these limitations, our data indicate that serum EL concentration would be a better indicator than HDL-c for CAD and in-stent restenosis. Furthermore, combining the three lipases provided a significantly higher predictive power than HDL-c or each lipase alone for CAD.

\section{Conclusions}

Serum EL, HL, and LPL concentrations were all simultaneously independent risk factors for CAD, and only serum EL concentration was an independent risk factor for in-stent restenosis. Crucially, the combination of the three lipases as multiple risk factors provided strong predictive power for CAD and made it possible to identify populations at high risk, thus providing effective interventions earlier than was previously feasible.

\section{Acknowledgments}

These studies were supported by the grant from the Medical Engineering Cross Research Fund of Shanghai JiaoTong Univeristy (YG2015ZD03).

\section{Conflict of Interest Statement}

All authors declare that they have no conflicts of interest.

\section{References}

1) Perez-Mendez O, Pacheco HG, Martinez-Sanchez C and Franco M: HDL-cholesterol in coronary artery disease risk: function or structure? Clin Chim Acta, 2014; 429: $111-122$

2) Field PA and Vasan RS: LDL-Cholesterol Is Not the Only Clinically Relevant Biomarker for Coronary Artery Disease or Acute Coronary Syndrome. Clin Pharmacol Ther, 2018; 104: 232-234

3) Jaye M, Lynch KJ, Krawiec J, Marchadier D, Maugeais C, Doan K, South V, Amin D, Perrone M and Rader DJ: A novel endothelial-derived lipase that modulates HDL metabolism. Nat Genet, 1999; 21: 424-428

4) Wong H, Davis RC, Nikazy J, Seebart KE and Schotz MC: Domain exchange: characterization of a chimeric lipase of hepatic lipase and lipoprotein lipase. Proc Natl Acad Sci U S A, 1991; 88: 11290-11294

5) Goldberg IJ: Lipoprotein lipase and lipolysis: central roles in lipoprotein metabolism and atherogenesis. J Lipid Res, 1996; 37: 693-707

6) Hirata K, Dichek HL, Cioffi JA, Choi SY, Leeper NJ, Quintana L, Kronmal GS, Cooper AD and Quertermous $\mathrm{T}$ : Cloning of a unique lipase from endothelial cells extends the lipase gene family. J Biol Chem, 1999; 274: $14170-14175$

7) Badellino KO, Wolfe ML, Reilly MP and Rader DJ: Endothelial lipase concentrations are increased in metabolic syndrome and associated with coronary atherosclerosis. PLoS Med, 2006; 3: e22

8) Sun L, Ishida T, Miyashita K, Kinoshita N, Mori K, Yasuda T, Toh R, Nakajima K, Imamura $S$ and Hirata K: Plasma activity of endothelial lipase impacts high-density lipoprotein metabolism and coronary risk factors in humans. J Atheroscler Thromb, 2014; 21: 313-321

9) Santamarina-Fojo $S$, Gonzalez-Navarro $H$, Freeman $L$, Wagner E and Nong Z: Hepatic lipase, lipoprotein metabolism, and atherogenesis. Arterioscler Thromb Vasc Biol, 2004; 24: 1750-1754

10) Dugi KA, Brandauer K, Schmidt N, Nau B, Schneider JG, Mentz S, Keiper T, Schaefer JR, Meissner C, Kather $\mathrm{H}$, Bahner ML, Fiehn W and Kreuzer J: Low hepatic lipase activity is a novel risk factor for coronary artery disease. Circulation, 2001; 104: 3057-3062

11) Liu Y, Xu J, Tao W, Yu R and Zhang X: A Compound Heterozygous Mutation of Lipase Maturation Factor 1 is Responsible for Hypertriglyceridemia of a Patient. J Atheroscler Thromb, 2019; 26: 136-144

12) Miyashita K, Nakajima K, Fukamachi I, Muraba Y, Koga T, Shimomura Y, Machida T, Murakami M and Kobayashi J: A new enzyme-linked immunosorbent assay system for human serum hepatic triglyceride lipase. J Lipid Res, 2017; 58:1591-1597

13) Hitsumoto $T$, Ohsawa $H$, Uchi $T$, Noike $H$, Kanai $M$, Yoshinuma M, Miyashita Y, Watanabe H and Shirai K: Preheparin serum lipoprotein lipase mass is negatively related to coronary atherosclerosis. Atherosclerosis, 2000; 153: $391-396$

14) Rip J, Nierman MC, Wareham NJ, Luben R, Bingham SA, Day NE, van Miert JN, Hutten BA, Kastelein JJ, Kuivenhoven JA, Khaw KT and Boekholdt SM: Serum lipoprotein lipase concentration and risk for future coronary artery disease: the EPIC-Norfolk prospective population study. Arterioscler Thromb Vasc Biol, 2006; 26: 637642

15) Saiki A, Oyama T, Endo K, Ebisuno M, Ohira M, Koide N, Murano T, Miyashita Y and Shirai K: Preheparin serum lipoprotein lipase mass might be a biomarker of metabolic syndrome. Diabetes Res Clin Pract, 2007; 76: 93-101

16) Dugi KA, Schmidt N, Brandauer K, Ramacher D, Fiehn W and Kreuzer J: Activity and concentration of lipoprotein lipase in post-heparin plasma and the extent of coronary artery disease. Atherosclerosis, 2002; 163: 127-134

17) Andrus B and Lacaille D: 2013 ACC/AHA guideline on the assessment of cardiovascular risk. J Am Coll Cardiol, 2014; 63: 2886

18) Shirakawa T, Nakajima K, Shimomura Y, Kobayashi J, Stanhope K, Havel P, Machida T, Sumino H and Murakami M: Comparison of the effect of post-heparin and pre-heparin lipoprotein lipase and hepatic triglyceride lipase on remnant lipoprotein metabolism. Clin Chim Acta, 2015; 440: 193-200

19) Judkins MP: Selective coronary arteriography. I. A percutaneous transfemoral technic. Radiology, 1967; 89: 
815-824

20) Ishida T, Miyashita K, Shimizu M, Kinoshita N, Mori K, Sun L, Yasuda T, Imamura S, Nakajima K, Stanhope KL, Havel PJ and Hirata K: ELISA system for human endothelial lipase. Clin Chem, 2012; 58: 1656-1664

21) Shirakawa T, Nakajima K, Yatsuzuka S, Shimomura $Y$, Kobayashi J, Machida T, Sumino H and Murakami M: The role of circulating lipoprotein lipase and adiponectin on the particle size of remnant lipoproteins in patients with diabetes mellitus and metabolic syndrome. Clin Chim Acta, 2015; 440: 123-132

22) Pepe MS: The statistical evaluation of medical tests for classification and prediction, Oxford Univerisity Press, New York, USA, 2002

23) $\mathrm{MH} \mathrm{K}$ : Multivariable analysis: a practical guide for clinicians, 2nd Ed, Cambridge University Press, New York, USA, 2006

24) An X, Yu D, Zhang R, Zhu J, Du R, Shi Y and Xiong X: Insulin resistance predicts progression of de novo atherosclerotic plaques in patients with coronary heart disease: a one-year follow-up study. Cardiovasc Diabetol, 2012; 11 : 71

25) Inoue T, Croce K, Morooka T, Sakuma M, Node K and Simon DI: Vascular inflammation and repair: implications for re-endothelialization, restenosis, and stent thrombosis. JACC Cardiovasc Interv, 2011; 4: 1057-1066

26) Nishio K, Fukui T, Tsunoda F, Kawamura K, Itoh S, Konno N, Ozawa K and Katagiri T: Insulin resistance as a predictor for restenosis after coronary stenting. Int J Cardiol, 2005; 103: 128-134

27) Badellino KO, Wolfe ML, Reilly MP and Rader DJ: Endothelial lipase is increased in vivo by inflammation in humans. Circulation, 2008; 117: 678-685

28) Paradis ME, Badellino KO, Rader DJ, Deshaies Y, Couture P, Archer WR, Bergeron N and Lamarche B: Endothelial lipase is associated with inflammation in humans. J Lipid Res, 2006; 47: 2808-2813

29) Stefan N, Schafer S, Machicao F, Machann J, Schick F, Claussen CD, Stumvoll M, Haring HU and Fritsche A: Liver fat and insulin resistance are independently associated with the $-514 \mathrm{C}>\mathrm{T}$ polymorphism of the hepatic lipase gene. J Clin Endocrinol Metab, 2005; 90: 42384243

30) Huang Y, Li X, Wang M, Ning H, A L, Li Y and Sun C: Lipoprotein lipase links vitamin $\mathrm{D}$, insulin resistance, and type 2 diabetes: a cross-sectional epidemiological study. Cardiovasc Diabetol, 2013; 12: 17

31) Hirano T: Pathophysiology of Diabetic Dyslipidemia. J Atheroscler Thromb, 2018; 25: 771-782

32) Hitsumoto T, Takahashi M, Iizuka T and Shirai K: Relationship between preheparin lipoprotein lipase mass concentration in serum and bare metal stent restenosis. J Cardiol, 2006; 48: 65-73

33) Sairyo M, Kobayashi T, Masuda D, Kanno K, Zhu Y, Okada T, Koseki M, Ohama T, Nishida M, Sakata Y and
Yamashita S: A Novel Selective PPARalpha Modulator (SPPARMalpha), K-877 (Pemafibrate), Attenuates Postprandial Hypertriglyceridemia in Mice. J Atheroscler Thromb, 2018; 25: 142-152

34) Kobayashi J, Nohara A, Kawashiri MA, Inazu A, Koizumi J, Nakajima K and Mabuchi H: Serum lipoprotein lipase mass: clinical significance of its measurement. Clin Chim Acta, 2007; 378: 7-12

35) Miyashita K, Kobayashi J, Imamura S, Kinoshita N, Stanhope KL, Havel PJ, Nakajima K, Machida T, Sumino H, Nara M and Murakami M: A new enzyme-linked immunosorbent assay system for human hepatic triglyceride lipase. Clin Chim Acta, 2013; 424: 201-206

36) Andres-Blasco I, Herrero-Cervera A, Vinue A, MartinezHervas S, Piqueras L, Sanz MJ, Burks DJ and GonzalezNavarro H: Hepatic lipase deficiency produces glucose intolerance, inflammation and hepatic steatosis. J Endocrinol, 2015; 227: 179-191

37) Hitsumoto $T$, Takahashi M, lizuka T and Shirai K: Relationship between two AMI risk factors: low serum lipoprotein lipase mass and hypoadiponectinemia. J Atheroscler Thromb, 2011; 18: 148-156

38) Higgins LJ and Rutledge JC: Inflammation associated with the postprandial lipolysis of triglyceride-rich lipoproteins by lipoprotein lipase. Curr Atheroscler Rep, 2009; 11: 199-205

39) Kobayashi J, Maruyama T, Masuda M and Shinomiya M: Effect of atorvastatin treatment on lipoprotein lipase mass in the pre-heparin plasma in Japanese hyperlipidemic subjects. Clin Chim Acta, 2001; 314: 261-264

40) Chen F, Maridakis V, O'Neill EA, Hubbard BK, Strack A, Beals C, Herman GA and Wong P: The effects of simvastatin treatment on plasma lipid-related biomarkers in men with dyslipidaemia. Biomarkers, 2011; 16: 321-333

41) Berk P, II, Hoogerbrugge N, Stolk RP, Bootsma AH, Jansen $\mathrm{H}$ and Group DS: Atorvastatin dose-dependently decreases hepatic lipase activity in type 2 diabetes: effect of sex and the LIPC promoter variant. Diabetes Care, 2003; 26: 427-432

42) Endo K, Miyashita Y, Saiki A, Oyama T, Koide N, Ozaki $\mathrm{H}$, Otsuka M, Ito $\mathrm{Y}$ and Shirai K: Atorvastatin and pravastatin elevated pre-heparin lipoprotein lipase mass of type 2 diabetes with hypercholesterolemia. J Atheroscler Thromb, 2004; 11: 341-347

43) Kojima Y, Ishida T, Sun L, Yasuda T, Toh R, Rikitake Y, Fukuda A, Kume N, Koshiyama H, Taniguchi A and Hirata K: Pitavastatin decreases the expression of endothelial lipase both in vitro and in vivo. Cardiovasc Res, 2010; 87: 385-393

44) Tada H, Kobayashi J, Kawashiri MA, Miyashita K, Nohara A, Inazu A, Nakajima K, Mabuchi $\mathrm{H}$ and Yamagishi M: Changes in lipoprotein lipase and endothelial lipase mass in familial hypercholesterolemia during threedrug lipid-lowering combination therapy. Lipids Health Dis, 2016; 15: 66 
A
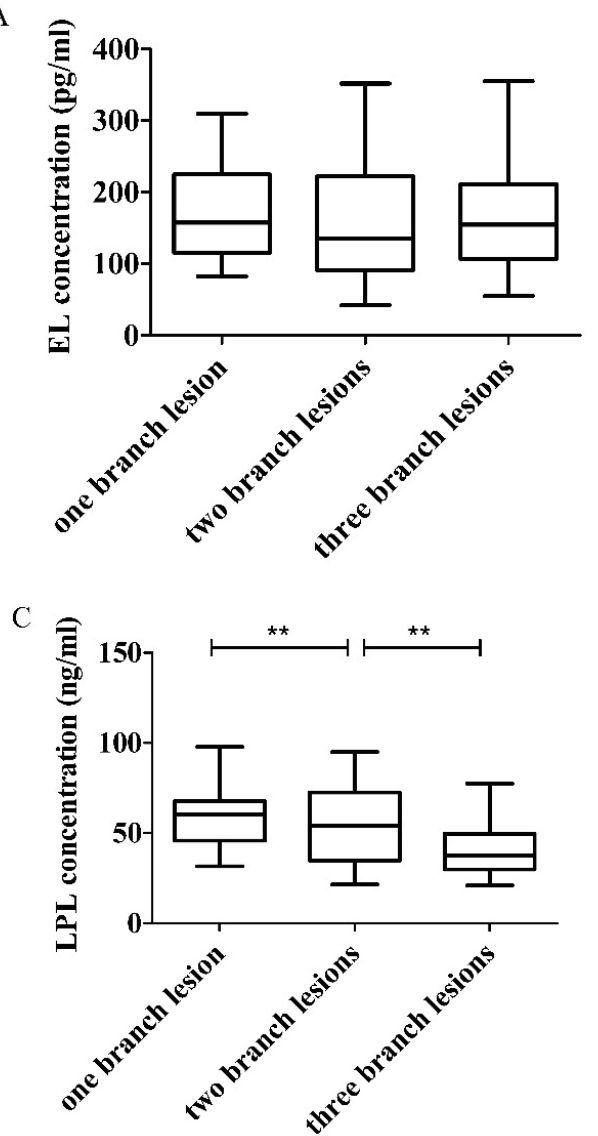

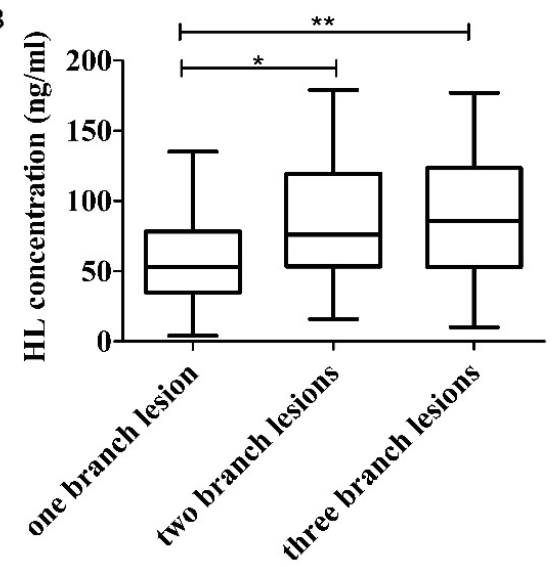

Supplementary Fig. 1. Serum LPL and HL concentrations were associated with the increasing number of coronary lesions

The patients with CAD were divided into three groups according to the numbers of coronary lesions ((one branch lesion $(n=33)$, two branch lesions $(n=22)$, three branch lesions $(n=31))$. A, $\mathrm{B}$, and C present the concentrations of serum EL, HL, and LPL among one, two and three branch lesions, respectively. Data are median $\pm \mathrm{IQR}$; Among the three groups comparisons were performed by one-way ANOVA with LSD; ${ }^{*} P<$ $0.05,{ }^{* *} P<0.01$. 
Supplementary Table 1. Multiple regression analysis of number of lesions

\begin{tabular}{lccc}
\hline & $\begin{array}{c}\text { Correlation } \\
\text { coefficient }\end{array}$ & $t$ value & $P$ value \\
\hline $\begin{array}{l}\text { Explanatory factor } \\
\text { Gender }\end{array}$ & 0.181 & 1.353 & 0.182 \\
AGE (years) & 0.194 & 1.450 & 0.153 \\
BMI $\left(\mathrm{kg} / \mathrm{m}^{2}\right)$ & 0.060 & 0.459 & 0.648 \\
SBP $(\mathrm{mmHg})$ & 0.070 & 0.452 & 0.653 \\
DBP $(\mathrm{mmHg})$ & 0.012 & 0.087 & 0.931 \\
FBP $(\mathrm{mmol} / \mathrm{L})$ & -0.013 & -0.022 & 0.983 \\
TG $(\mathrm{mmol} / \mathrm{L})$ & -0.061 & -0.344 & 0.732 \\
TCH $(\mathrm{mmol} / \mathrm{L})$ & 0.506 & 0.818 & 0.417 \\
HDL $(\mathrm{mmol} / \mathrm{L})$ & -0.132 & -0.613 & 0.542 \\
LDL $(\mathrm{mmol} / \mathrm{L})$ & -0.425 & -0.741 & 0.462 \\
EL $(\mathrm{pg} / \mathrm{mL})$ & -0.069 & -0.564 & 0.575 \\
HL $(\mathrm{ng} / \mathrm{mL})$ & 0.391 & 3.151 & $<0.01$ \\
LPL $(\mathrm{ng} / \mathrm{mL})$ & -0.369 & -3.061 & $<0.01$ \\
\hline Subordinate factor & & & \\
number of lesions $=1,2,3$ & & & \\
\hline
\end{tabular}

$\mathrm{R}^{2}=0.276, \mathrm{~F}$ value $=2.17, P<0.05,(n=86) ;$

BMI, body mass index; SBP, systolic blood pressure; DBP, diastolic blood pressure; FBG, fast blood glucose; TCH, total cholesterol; TG, total triglyceride; LDL-c, lowdensity lipoprotein cholesterol; HDL-c, high-density lipoprotein cholesterol. 